\title{
State-dependent performance of rats on a complex maze task
}

\author{
JEANNE M. STAHL, KAREN E. BRAKKE, and SHAWANA LEWIS \\ Morris Brown College, Atlanta, Georgia
}

\begin{abstract}
State-dependent learning occurs when information acquired in one chemical state fails to transfer or only partially transfers to another state. Thirty-five Long-Evans rats learned to run the Hampton Court maze and then were tested in an ABA design, alternating between administration of one of three doses of morphine sulfate $(6,10$, or $15 \mathrm{mg} / \mathrm{kg})$ and saline. At the two highest drug doses, regardless of direction of switch (saline to morphine or vice versa), the subjects' running time increased significantly after the first switch, but not at all or to a much lesser degree after the second switch, indicating possible state-dependency effects. Analysis of errors indicated that, after the first state change only, rats that had switched from morphine to saline committed errors immediately after the change under all three dose conditions, but those that switched from saline to morphine continued to run the maze without error. The results of this study indicate that morphine-related state changes can create temporary disruptions in performance--independently of direct drug effects-on a task with a long learning curve such as this one.
\end{abstract}

Within the field of psychopharmacology, the term statedependent learning (SDL) refers to the question of whether something learned in one chemical state can be readily retrieved while the individual is experiencing a different internal chemical state, or whether efficient access to the information is specific to the state under which it was originally learned. Historically (during the 19th and early 20th centuries), the phenomenon of state dependency was often called "dissociation" because information acquired in an altered chemical state appeared to be disconnected from "memories [that] were accessible to consciousness" (Overton, 1991, p. 253) in an unaltered state. SDL was often cited in reference to amnestic states such as alcoholinduced "blackouts" or other "fugue states" and was reported in clinical studies and anecdotally until interest in this topic waned in the early 1900s (Overton, 1991).

\section{State Dependency and Drug Discrimination}

SDL research experienced a resurgence of interest from the 1950s through the 1970s (Overton, 1991) and gave rise to drug discrimination (DD) protocols, which are now widely used to assess the stimulus properties of drugs. Although the same mechanisms may underlie both SDL and DD (Overton, 1991; see Colpaert \& Koek, 1994, for a dissenting opinion), there are conceptual and pro-

\footnotetext{
This research was supported by National Institute on Drug Abuse/Minority Institutions Research Development Program Grant 5R24DA07256. Some of the data from this project were presented at the 59th annual meeting of the College on Problems of Drug Dependence in Nashville, TN (June 1997). The authors thank Gary Lawrence, Rodney Swift, and Natalie Colbert for their assistance with this project. Correspondence should be addressed to J. M. Stahl, Department of Psychology, Morris Brown College, 643 M. L. King Jr. Dr. NW, Atlanta, GA 30314 (e-mail: jstahl@morrisbrown.edu).
}

cedural differences between the two domains as they exist today. DD researchers ask whether a subject can perceive different drug states, evidenced by selection among competing responses performed under the different states (Colpaert, 1982). After being trained to discriminate the baseline states (often drug vs. no drug), the subject is given either a different drug or a different dosage of the same drug. The extent to which the baseline drugstate response extends to the new state is the extent to which the original state is believed to generalize to the new drug or dose. Conversely, the extent to which responses under the states differ is the extent to which they are said to be discriminated from one another. In DD research, it is necessary to explicitly train two or more initial responses to the different states; techniques have usually involved fairly simple response topographies such as leverpressing, T-mazes, or shock avoidance chambers ( $\mathrm{Col}-$ paert, Niemegeers, \& Janssen, 1980; Glennon, Rosencrans, \& Young, 1982).

In most contemporary SDL research, by contrast, an individual learns a single response under one drug state (Jackson, 1995; Nakagawa, Ishibashi, Yoshii, \& Tagashira, 1995). When that response is stable, the drug state is then changed, and the subject is tested again on the same task to determine whether what was learned has transferred to the new state. If there is no decrement in performance after the state change, the learning has transferred completely, and no SDL has occurred. If, however, there is a decrement in performance that does not appear to be linked to a drug effect or other artifact, SDL may explain the disruption in behavior.

SDL has been more difficult to establish than DD performance. For example, the drug dosage needed to demonstrate SDL typically has been higher than that needed to elicit DD (Overton, 1974). In many cases, in fact, doses 
that have been sufficient to produce SDL have also been large enough to create behavioral deficits (e.g., sedation) that make interpretation difficult. Because of these difficulties, in recent years emphasis has been placed on DD research rather than on establishing the parameters of SDL (Colpaert \& Koek, 1994; Eich, 1980).

Some evidence of drug-related SDL has been established, nevertheless (Colpaert, 1986; Jackson, 1995; Nakagawa \& Iwasaki, 1995, 1996). Drugs that have produced evidence of SDL have typically been centrally acting drugs with substantial abuse potential, such as diazepam (Jackson, 1995; Nakagawa, Iwasaki, Ishima, \& Kimura, 1993) or ethanol (Hunt, Molina, Spear, \& Spear, 1990; Nakagawa \& Iwasaki, 1995). These drugs typically affect one neurotransmitter system in the brain or more. Because the data from drug studies often mimic data obtained by manipulating external sensory stimuli, many investigators believe that both the interoceptive and exteroceptive stimuli tap into the same neural mechanisms or conditioning processes (Bliss, 1974; Järbe \& Swedberg, 1982; Overton, 1991). That is, perception of internal cues resulting from the change in state is altered in some way and therefore provides different antecedent conditions than were present in the original learning state. Sensitive to the altered kinesthetic, or physiological, cues, the animal therefore responds differently to the task, even though the external conditions remain the same.

One of the difficulties in establishing the existence of state-dependent behavior is the necessity of ruling out other drug-related performance effects, or combinations of such effects, as a cause of behavioral alterations that occur after the state change. As Overton (1984) notes, performance-related explanations can include drug effects that affect motor control, motivation, withdrawal processes, and other behaviors that have an impact on responses. Combinations of these effects are difficult to rule out, especially in a $2 \times 2$ design (i.e., one group changes from the drug to the no-drug state, and the other changes in the reverse direction). For example, an animal that displays an increase in response latency upon removal of a drug state may be experiencing withdrawal symptoms. Use of alternative designs that control for order effects, withdrawal, and other confounds is essential for furthering the study of state-dependency phenomena (see Overton, 1984).

Despite years of theoretical interest, then, the status of SDL is still unclear, and its presence may be overlooked in studies of drug effects. Determining the robustness of SDL as a phenomenon in its own right is important, however, and has many implications for human psychopharmacology and abuse treatment. To date, the tasks that have been used to assess SDL in nonhumans have been the same as those used in DD, with simple response topographies. Such responses that are learned quickly may not be the most appropriate for SDL studies. Instead, a more complex task that incorporates multiple steps or decisions, and therefore places a greater load on the animal's cognitive processes, may be useful because it may be more sensitive than simpler tasks to subtle performance decrements that might accompany SDL. Interestingly, Colpaert (1986) has found evidence of SDL with chlordiazepoxide in a leverpressing procedure that has a simple response topography but that entails a relatively long learning curve and a response time dependent measure. This supports the suggestion that the sensitivity of the task and the dependent measure may be important determinants in a study's ability to detect SDL.

\section{The Hampton Court Maze}

The Hampton Court maze was adapted from the garden maze at the Hampton Court estate in England by Small (1901) around the turn of the century. Small used this maze to examine a variety of the rat's behaviors and learning processes. The task for the subject combines elements of a go/no-go task (there is a single goal with reinforcement) with the choice-related aspects of alternative response tasks (the subject may be correct or incorrect in the moves it makes). Such a task, with its varied pathways and multiple choice points, provides a relatively ecologically valid problem for a rat in a laboratory situation while yielding data sensitive to subtle changes in performance.

\section{Morphine and State Dependency}

Morphine is a widely used opioid analgesic that has high abuse potential in humans. Although its primary effects do not include memory impairment, its centrally acting mechanisms make it a candidate for producing state-dependent performance. Nishimura, Shiigi, and Kaneto (1990), using passive shock-avoidance procedures, determined that pretraining morphine suppressed the acquisition phase of memory in mice. When morphine was again given before a test, memory recovered to, or above, the control level, suggesting the presence of state-dependency effects on this task.

Discrimination of morphine from the nondrugged state has occurred reliably in rats at interperitoneally injected doses above $3 \mathrm{mg} / \mathrm{kg}$ (see, e.g., Kaempf \& Kallman, 1987), well below the amounts used in the present study. This study was designed to present the rat with a task that provides a long learning (or relearning) curve that may be more sensitive to morphine-related state dependency effects than a simple operant response or two-choice discrimination task. To this end, we used the Hampton Court maze, which rats take several trials to learn correctly. With this task, state-related disruption can be measured in terms of both response time and appearance of errors.

\section{METHOD}

\section{Subjects}

The subjects were 35 naive male Long-Evans hooded rats (Charles River Laboratories, Portage, MI). Each of the six test groups included 6 rats, with the exception of the group that was initially injected with the highest dose of morphine $(15 \mathrm{mg} / \mathrm{kg})$. At this dose, several animals exhibited behavioral sensitization to the drug and began to chew their forepaws or engage in other perseverative be- 
haviors that interfered with their maze learning. The decision was made to include only the 5 rats in this group that did not display such behaviors after receiving $15 \mathrm{mg} / \mathrm{kg}$ of morphine.

All rats were approximately 90 days old at the start of testing and were housed individually in hanging wire cages in a room with a 12:12-h light:dark cycle (lights on at 7 a.m.). The animals were maintained at $85 \%$ of their ad-lib weight adjusted periodically for growth; the body weights were approximately $300-380 \mathrm{~g}$ during the course of testing.

\section{Apparatus \\ The Hampton Court maze (Figure 1) was adapted for this study. The asymmetric maze had 42 turns and seven choice points on its single correct path. The maze was $150 \mathrm{~cm}$ wide, $100 \mathrm{~cm}$ deep (front to back), and $15 \mathrm{~cm}$ high. The alleys were $7 \mathrm{~cm}$ wide. A $26 \times 32 \mathrm{~cm}$ goalbox in the center of the maze contained a small dish baited with approximately $20 \mathrm{~g}$ of moistened rodent chow. At the start of each trial, the subject was placed in a clear Plexiglas startbox $(21 \times 11$ $\times 11 \mathrm{~cm}$ ), which opened into the maze via a manually operated Plexiglas guillotine door. The maze in which most rats were tested was constructed out of Thermasheath (a lightweight insulation ma- terial) painted flat black with a wire mesh cover across its top. How- ever, the last cohort of rats - one from each of the six groups-was tested in a newly constructed black Plexiglas maze with a clear Plexiglas cover. The maze's material did not appear to affect the rats' performance.}

\section{Procedure}

Handling and adaptation. Prior to the beginning of maze training, the rats were handled for $5 \mathrm{~min}$ per day for 5 days in order to habituate them to the experimenter. Five individuals served as the experimenters, but each animal had the same experimenter throughout the study. On the last 3 habituation days, the experimenter placed the rat in the closed-off goalbox with a dish of food for $30 \mathrm{~min}$. This was done in order to adapt the animals to the test environment. Although no drugs were administered to any animals during this adaptation period, there is no evidence that this procedure differentially affected the performance of the rats under different drug conditions. Instead, the procedure served to habituate the subjects to the apparatus, as was evidenced by their behavior and

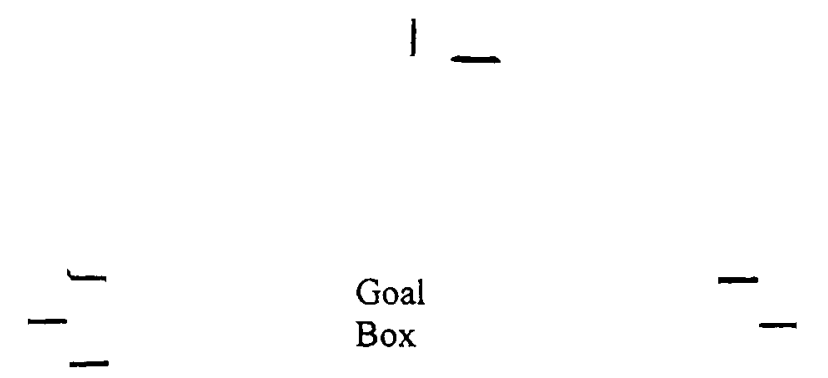

the markedly reduced incidence of urination and defecation by the animals between the 1st day of adaptation and the Ist day of testing, regardless of drug state.

Drug administration. Thirty minutes before being placed in the maze, the subjects were injected intraperitoneally (i.p.) either with saline or with morphine sulfate solution (Elkins-Sinn, Cherry Hill, $\mathrm{NJ}$ ). The animals under the morphine condition received one of three doses of drug: 6,10 , or $15 \mathrm{mg} / \mathrm{kg}$. Injections were given once daily, typically 5 days per week. Experimenters were blind to the drug condition of the subjects on each day of training and testing. Table 1 provides an overview of the dose condition assignments.

Maze training. Each rat was trained and tested individually. Each day, 30 min after injection, the rat was carried to the maze test room and placed in the goalbox, where it was allowed to eat for $30 \mathrm{sec}$. It was then placed in the transparent startbox for $60 \mathrm{sec}$. After this period had elapsed, the experimenter waited for the rat to indicate that it was ready to run by orienting toward, and standing with its nose in proximity to, the exit door (the rats usually were ready long before the minute had passed; often they scratched at or tried to lift the door in an attempt to get into the maze), and then the experimenter lifted the door until the rat had exited. As the rat explored the maze, the experimenter traced the animal's path with paper and pencil and noted errors. Errors were defined as occurring when a rat stepped in the wrong direction at one of the seven choice points or reversed its path while heading in the correct direction (i.e., turned around and went back along the same path) anywhere in the maze. Latency to leave the startbox and running time from startbox tó goalbox were also recorded.

Each animal ran five consecutive trials per day, and was given $5 \mathrm{~min}$ to reach the baited goalbox during each trial. If the subject successfully found the food on a given trial, it was allowed to eat for $30 \mathrm{sec}$ before being returned to the startbox for the next trial or to its home cage at the end of the session. If the rat failed to reach the goalbox, it was returned to the startbox without receiving any food.

Testing: Switching drug conditions. Criterial performance for successfully learning the maze was defined as running with stable mean running time (usually under $30 \mathrm{sec}$, with a variation of $10 \mathrm{sec}$ or less between days) while producing less than one error per day over 3 consecutive days. Once these criteria had been met, the rat was switched either from the saline condition to the morphine condition or vice versa as appropriate. The subjects that changed from the saline condition to the drug condition at this point received a predetermined dose of 6-, 10-, or $15-\mathrm{mg} / \mathrm{kg}$ morphine sulfate.

Because the subjects often experienced decrements in performance immediately after the state change, many of the rats had to relearn how to run the maze efficiently. The testing continued with each subject in the new drug state until the subject met the same criteria as had been established in the first phase of learning. After again reaching criterial performance under the new condition, each rat was returned to its initial chemical state (i.e., it was again given the dose under which it had originally learned the maze) until the criteria were met once again. Throughout all the test sessions and conditions, latency to leave the startbox, running time, and number of errors were recorded for each trial.

\section{RESULTS}

\section{1}

$\leftarrow$ Start Box

Figure 1. The Hampton Court maze. The rat was placed in a startbox and ran to the goalbox, which was baited with food.

\section{Sessions to Criterion}

The number of sessions (with five trials per session) needed for individual rats to meet the criteria for successfully learning the maze under the initial condition ranged from 8 to 39 . Although the group means ranged from 14 days (Group 4 on $6-\mathrm{mg} / \mathrm{kg}$ morphine) to 24 days (Group 1 on saline), none of the differences between the 
Table 1

\begin{tabular}{cclll}
\multicolumn{5}{c}{ Table 1 } \\
Group & $n$ & Initial Dose & 2nd (Postswitch) Dose & 3rd Dose \\
1 & 6 & saline & 6-mg/kg MS & saline \\
2 & 6 & saline & $10-\mathrm{mg} / \mathrm{kg} \mathrm{MS}$ & saline \\
3 & 6 & saline & $15-\mathrm{mg} / \mathrm{kg} \mathrm{MS}$ & saline \\
4 & 6 & $6-\mathrm{mg} / \mathrm{kg} \mathrm{MS}$ & saline & $6-\mathrm{mg} / \mathrm{kg} \mathrm{MS}$ \\
5 & 6 & $10-\mathrm{mg} / \mathrm{kg} \mathrm{MS}$ & saline & $10-\mathrm{mg} / \mathrm{kg} \mathrm{MS}$ \\
6 & 5 & $15-\mathrm{mg} / \mathrm{kg} \mathrm{MS}$ & saline & $15-\mathrm{mg} / \mathrm{kg} \mathrm{MS}$ \\
Note-MS, morphine sulfate. & &
\end{tabular}

groups were significant $[F(5,29)=1.87$, n.s.], in part because individual differences within the groups were large.

After the first state change, the rats in all six groups met the criteria in significantly fewer days than they took to initially learn the maze $[t(5) \geq 2.94, p<.05]$. The number of days in the second state was, however, greater than the minimum of 3 days in all the groups, indicating some disruption of performance for at least a few of the sessions. Group means ranged from 6.3 sessions in the subjects that switched from saline to $10-\mathrm{mg} / \mathrm{kg}$ morphine, to 10.0 sessions in the subjects that switched from saline to $15-\mathrm{mg} / \mathrm{kg}$ morphine.

All of the groups of rats met errorless criterial performance rapidly after the second and third state changes (i.e., when the states were those that had been experienced in the maze before). The mean days to criterion after the second switch ranged from 3.5 to 4.8 , very close to the minimum needed ( 3.0 days) with the criteria defined as they were.

\section{Running Times}

Mean criterial running times for the final session of the initial learning condition are shown in Table 2 for the saline, 6-, 10-, and $15-\mathrm{mg} / \mathrm{kg}$ subject groups. According to a Tukey B post hoc test, there were no significant differences in the speed with which the rats ran the maze by the end of the training period, with the exception of the $15-\mathrm{mg} / \mathrm{kg}$ group, which took an average of $27.3 \mathrm{sec}$ to complete the maze, as opposed to $18.2-20.3 \mathrm{sec}$ for all other groups.

The pattern of disruption after the first and second state changes depended on the dose of morphine involved, as can be seen in Figures $2 \mathrm{~A}-2 \mathrm{C}$. There was no correlation $(r=.06)$ between number of days required to meet criterion and the increase in running time on the day after the first switch, suggesting that disruption was not related to overlearning or familiarity with the task.

At the lowest dose $(6 \mathrm{mg} / \mathrm{kg}$; Figure $2 \mathrm{~A})$, there was only a slight, nonsignificant increase in running time in both the morphine-to-saline $[16.0 \mathrm{sec} ; t(5)=1.99$, n.s.] and saline-to-morphine conditions $[1.8 \mathrm{sec} ; t(5)=0.53$, n.s.] after the first switch. The second switch produced an increase only of $9.4 \mathrm{sec}[t(5)=1.99$, n.s.] when the rat moved back from $6-\mathrm{mg} / \mathrm{kg}$ morphine to saline, and there was a negligible increase in running time [0.4 sec; $t(5)=0.12$, n.s.] when the second switch was from saline to the low dose of morphine.

The $10-\mathrm{mg} / \mathrm{kg}$ groups produced a pattern of results that was consistent with a "classic" state-dependency interpretation (Figure 2B). The first switch produced a bidirectional increase in running time: $35.6 \mathrm{sec}$ in $0-10$ $0[t(5)=2.87, p<.05]$ and $77.6 \mathrm{sec}$ in $10-0-10[t(4)=$ $2.35, p<.05]$. The second switch was not significant in either direction: $7.3 \mathrm{sec}$ for $0-10-0[t(5)=0.93, \mathrm{n} . \mathrm{s}$.$] and$ $1.6 \mathrm{sec}$ for $10-0-10[t(5)=0.73$, n.s. $]$.

With the $15-\mathrm{mg} / \mathrm{kg}$ dose, an apparent sedative drug effect that was independent of state dependency emerged (Figure 2C). When switched from saline to this high dose of morphine, many rats did not complete the maze on many or all of the 1st day's (postswitch) trials. These trials were assigned a value of $300 \mathrm{sec}$ for purposes of analysis. With these trials included, the mean increase in running time on the day after the switch in this group was much larger than in the $10-\mathrm{mg} / \mathrm{kg}$ condition, averaging $173.9 \mathrm{sec}[t(5)=2.81, p<.05]$. Omitting these trials and including only the first five completed trials still yielded a significant increase of $61.9 \mathrm{sec}[t(5)=3.30, p<.05]$. The switch from $15-\mathrm{mg}$ morphine to saline produced a significant increase in running time of $39.7 \mathrm{sec}[t(4)=$ $3.38, p<.05]$. If the second switch was from saline to $15-$ $\mathrm{mg} / \mathrm{kg}$ morphine, there was an increase in running time of $20.6 \mathrm{sec}[t(4)=0.99$, n.s.]; this group was the only one of the six in which an increase of more than $10 \mathrm{sec}$ appeared after the second switch, although this increase was still not statistically significant and may be attributed to sedation from administration of the large dose of morphine after several days without it. Switching from 15-mg morphine back to saline produced only a $1.2-\mathrm{sec}$ increase in running time $[t(5)=0.52$, n.s. $]$.

\section{Errors}

Analysis of errors made during the first session after the dosage change yielded an asymmetrical pattern of results, illustrated in Figure 3. The rats that switched from any dose of morphine to saline made significantly more errors on the day of the switch (mean for all $=5.41$, $S D=5.86$ ) than did the rats that changed from saline to

\section{Table 2}

Preswitch Mean Running Times

(in Seconds, With Standard Deviations) for Groups of Subjects

$\begin{array}{cllcl}\text { Group } & \text { Initial Dosage } & & & \\ 1 & \text { Condition } & n & M & S D \\ 2 & \text { saline } & 6 & 20.1 & 4.2 \\ 3 & \text { saline } & 6 & 18.2 & 4.9 \\ 4 & \text { saline } & 6 & 19.5 & 4.3 \\ 5 & \text { 6-mg/kg MS } & 6 & 20.3 & 5.1 \\ 6 & 10-\mathrm{mg} / \mathrm{kg} \mathrm{MS} & 6 & 20.0 & 4.3 \\ & 15-\mathrm{mg} / \mathrm{kg} \text { MS } & 5 & 27.3^{*} & 4.3\end{array}$

Note-Criterion was three sessions for mean running time. MS, morphine sulfate. *Significant difference at $p=.05$, post hoc Tukey test. 


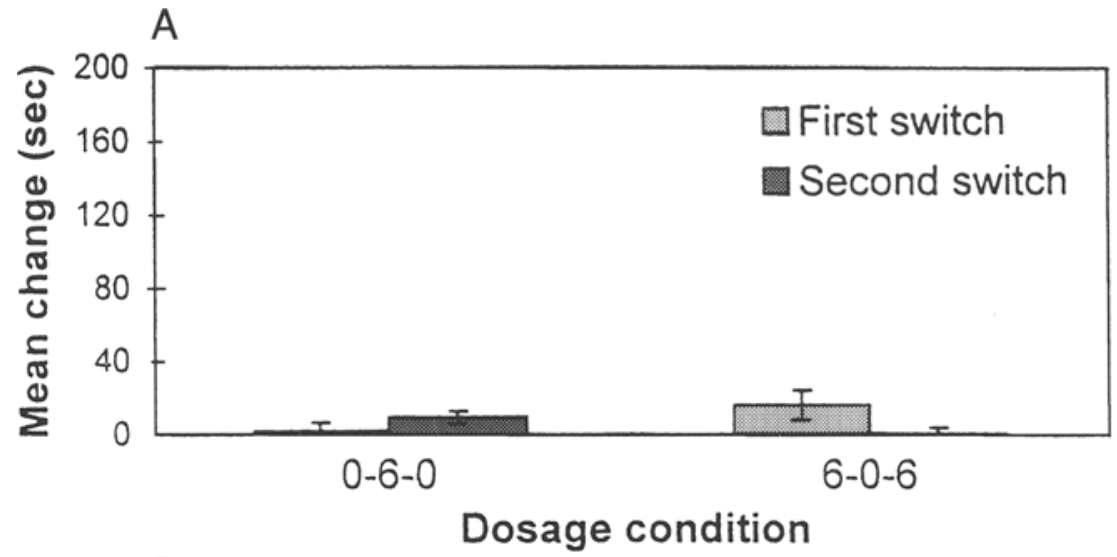

B

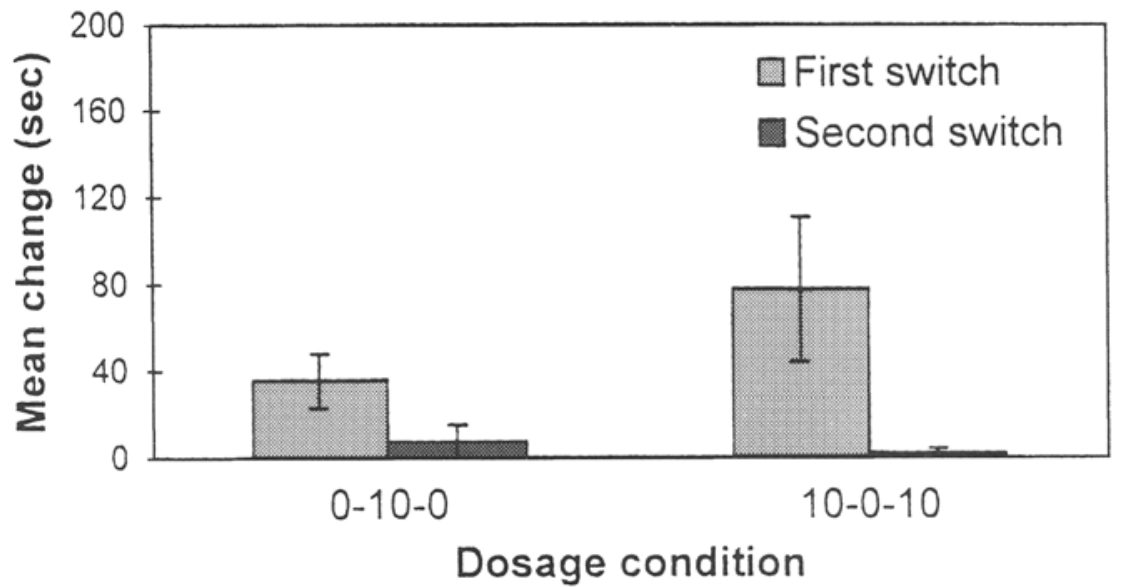

C

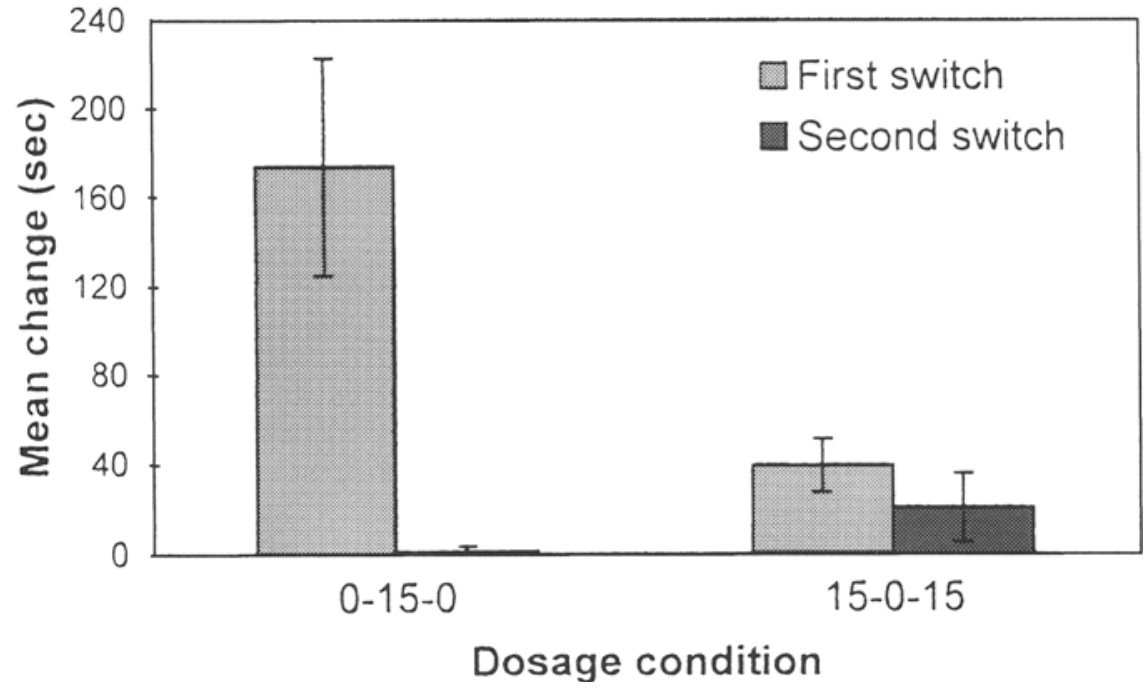

Figure 2. Increases in the mean number of seconds needed to complete the maze during the first session after a dosage switch relative to the day before the switch. Each graph represents a different dose of morphine. For each group of rats, the first bar represents the day after the first switch (e.g., from saline to $6 \mathrm{mg} / \mathrm{kg}$ in the 0-6-0 group); the second bar represents the day after the rats were switched back to their original state (e.g., from $6 \mathrm{mg} / \mathrm{kg}$ back to saline in the 0-6-0 group). Error bars indicate the standard error of the mean for each group of rats. 


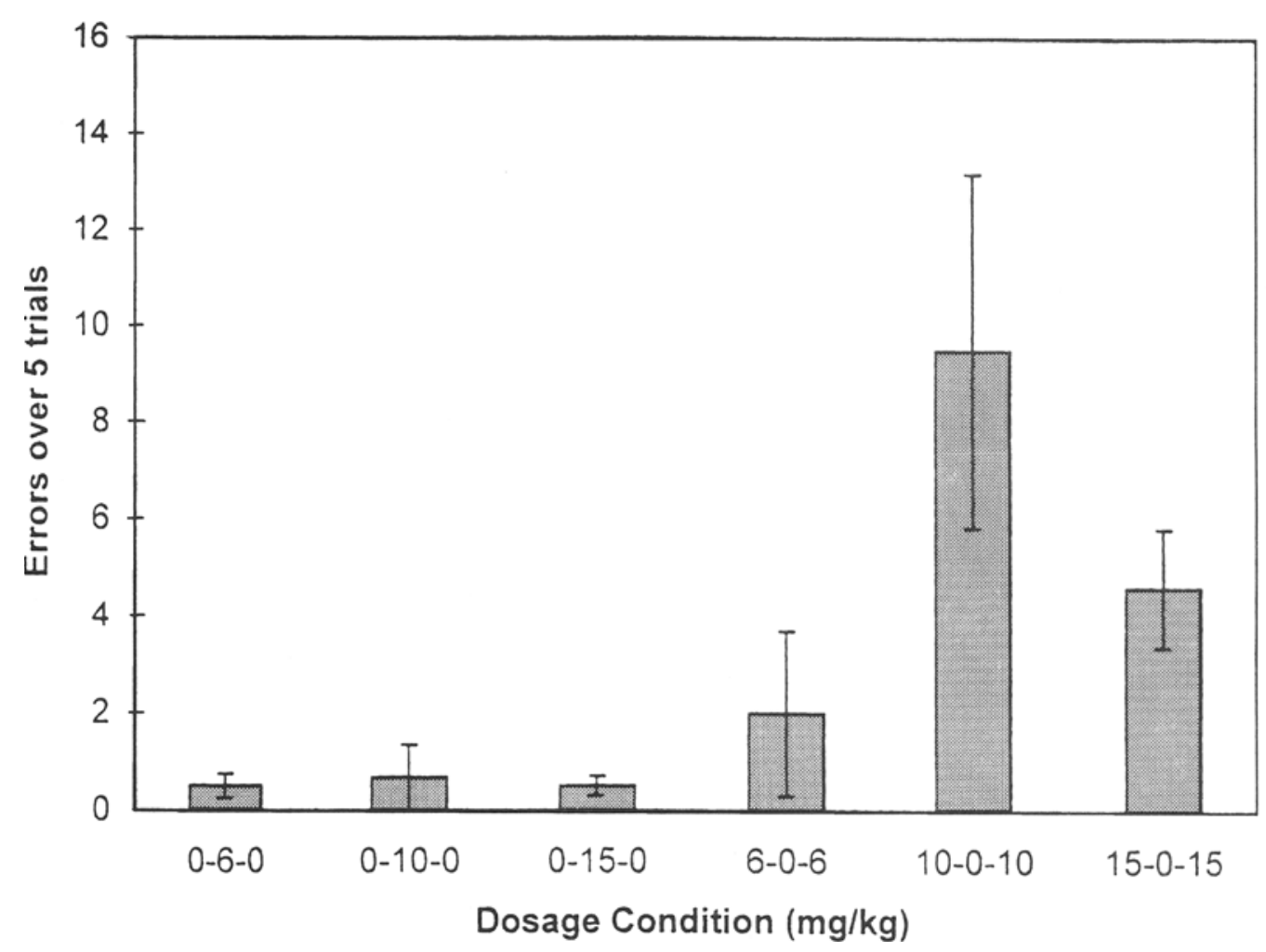

Figure 3. Mean numbers of errors made while running the maze during the first session after the dosage switch for each group of rats. Error bars indicate the standard error of the mean for each group of rats.

morphine $(M=0.56, S D=1.04)[F(1,34)=12.80, p<$ $.05]$. The effect of dose was not significant $[F(2,33)=$ 1.81, n.s.].

\section{GENERAL DISCUSSION}

In this study, we have evaluated the existence of statedependent performance on a task that places a relatively heavy load on a rat's cognitive processes. We have also addressed interpretive questions facing earlier research on this issue by adopting an experimental design that incorporates several dose levels as well as multiple state changes within each animal. Through the use of these procedures and the Hampton Court maze apparatus, we believe that we have established behavior that is best interpreted as state-dependency.

The pattern of results was complex, but on the whole it was more consistent with a state-dependency interpretation than with other explanations. Changing the chemical state under which the rat was operating disrupted its performance on the maze task temporarily. Furthermore, this disruption occurred only when the change was to a chemical state under which the animal had not yet experienced the task; subsequent changes between familiar states did not affect performance at all in most groups. Sedation appeared to affect running times only at the highest morphine dose $(15 \mathrm{mg} / \mathrm{kg})$, and even then it did not appear to fully account for the magnitude of the disruption in the $15-\mathrm{mg} / \mathrm{kg}$ groups relative to the other state changes. Other drug-related effects, such as withdrawal, may play a role in some of the disruptions, but they do not provide a comprehensive explanation. Nor, do we believe, do the subjects' performances subscribe to patterns attributable to central-tendency performance explanations. These explanations hold that in a task such as this, rats are likely to run more slowly or to make errors at some point, and that the criterion set in this study merely represents the maximal error-free performance in any condition.

Although we did not employ the use of same-state control groups (in which animals continue to receive the same dose of morphine after reaching criterion), and it is therefore theoretically possible that our definition of criterion matched a point at which animals' performance would deteriorate under any condition, we believe that the consistent performance of the rats that received the low (6-mg/kg) dose of the drug, as well as the consistent performance of all the rats after the second state change, argues against this potential challenge to a state-dependency interpretation.

The most parsimonious explanation, then, appears to draw on the state change itself as a source of disruption in the rats' performance. That the disruption was temporary-lasting from a few trials to a few days-indicates 
that, rather than information's being lost under an alternative state, there is some sort of "routing" problem in the initial retrieval of the necessary data. The interference with the retrieval of the information, rather than with the storage, is consistent with findings of other state-dependency studies (e.g., Lowe, 1982).

The nature of the processes that interfere with access to the information necessary to solve the maze efficiently is not resolved. However, there is evidence from previous studies with both humans and animals that state-dependent performance may be cue based (Petersen, 1979; Pusakulich \& Nielson, 1976). For example, if salient external cues are provided when the subject is responding, state-dependent effects are reduced. The existence or absence of a particular drug in an organism's system may provide interoceptive cues that function similarly to exteroceptive cues in guiding responses within a particular context. It has also been suggested that the presence of a drug alters the availability of different cue systems to the responding subject. Pusakulich and Nielson, for example, have suggested that nondrugged rats can use both cognitive mapping and response sequences to solve a water maze, but that subjects under the influence of a drug (in this case, pentobarbital) must rely on response sequences alone in order to solve the same task. O'Keefe and Nadel (1978) have made similar claims regarding animals with hippocampal lesions. These hypotheses await further testing with the present task, but pilot results with a few animals experiencing maze rotation in the test room suggest that altering the external environment can affect rats' performance in ways similar to those observed with morphine state dependency.

Although we have taken an exclusively behaviororiented approach to assessing state dependency, the results are in good accord with Hebb (1949), who claimed that the cell assemblies responsible for memory processes functioned "most efficiently [italics added] under the physiological conditions present when they were established, and would function less efficiently [italics added] in other physiological conditions" (Overton, 1984, p. 64). In the present study, this loss of efficiency after a state change is reflected behaviorally by the rats' taking longer to reach the goal and/or making errors along the way. It does not appear that the entire route must be relearned, only that efficient performance of the task is initially disrupted. Hence, use of the term statedependent performance may be more appropriate than state-dependent learning to describe the phenomenon that is evidenced here. This distinction is important and will be of value in designing and interpreting future research on state dependency in both animals and humans.

\section{REFERENCES}

BuIss, D. K. (1974). Theoretical explanations of drug-dissociated behaviors. Federation Proceedings, 33, 1787-1796.

COLPAERT, F. C. (1982). The pharmacological specificity of opiate drug discrimination. In F. C. Colpaert \& J. L. Slangen (Eds.), Drug dis- crimination: Applications in CNS pharmacology (pp. 3-16). Amsterdam: Elsevier.

Colpaert, F. C. (1986). A method for quantifying state-dependency with chlordiazepoxide in rats. Psychopharmacology, 90, 144-146.

ColPaERT, F. C., \& Koek, W. (1994). Empirical evidence that the state dependence and drug discrimination paradigms can generate different outcomes. Psychopharmacology, 120, 272-279.

Colpaert, F. C., Niemegeers, C. J. E., \& Janssen, P. A. J. (1980). Factors regulating drug cue sensitivity: The effect of training dose in fentanyl-saline discrimination. Neuropharmacology, 19, 705-713.

EICH, J. E. (1980). The cue-dependent nature of state-dependent retrieval. Memory \& Cognition, 8, 157-173.

Glennon, R. A., Rosencrans, J. A., \& Young, R. (1982). The use of the drug discrimination paradigm for studying hallucinogenic agents: A review. In F. C. Colpaert \& J. L. Slangen (Eds.), Drug discrimina tion: Applications in CNS pharmacology (pp. 69-96). Amsterdam: Elsevier.

HeBB, D. O. (1949). The organization of behavior, a neuropsychological theory. New York: Wiley.

Hunt, P. S., Molina, J. C., Spear, L. P., \& Spear, N. E. (1990). Ethanol-mediated taste aversions and state-dependency in preweanling (16-day-old) rats. Behavioral \& Neural Biology, 54, 300-322.

JACKSON, A. (1995). State-dependent effects of atypical benzodiazepinereceptor agonists. Psychopharmacology, 119, 399-404.

JÄRBE, T. U. C., \& SWEDBERG, M. D. B. (1982). A conceptualization of drug discrimination learning. In F. C. Colpaert \& J. L. Slangen (Eds.), Drug discrimination: Applications in CNS pharmacology (pp. 327341). Amsterdam: Elsevier.

KAEMPF, G. L., \& Kallman, M. J. (1987). A comparison of testing procedures on the discriminative morphine stimulus. Psychopharmacology, 91, 56-60.

LOWE, G. (1982). Alcohol-induced state-dependent learning: Differentiating stimulus and storage hypotheses. Current Psychological Research, 2, 215-222.

Nakagawa, Y., Ishibashi, Y., YoshiI, T., \& Tagashira, E. (1995). Muscimol induces state-dependent learning in Morris water maze task in rats. Brain Research, 681, 126-130.

NAKAGAWA, Y,, \& IWASAKI, T. (1995). Involvement of benzodiazepine/ GABA-A receptor complex in ethanol-induced state-dependent learning in rats. Brain Research, 686, 70-76.

NAKAGAWA, Y., \& IWASAKI, T. (1996). Ethanol-induced state-dependent learning is mediated by 5-hydroxytryptamine ${ }_{3}$ receptors but not by $\mathrm{N}$ methyl-D-aspartate receptor complex. Brain Research, 706, 227-232.

NAKAGAWA, Y., IWASAKI, T., Ishima, T., \& KimURA, K. (1993). Interaction between benzodiazepine and GABA-A receptors in statedependent learning. Life Sciences, 52, 1935-1945.

Nishimura, M., Shilgi, Y., \& Kaneto, H. (1990). State dependent and/or direct memory retrieval by morphine in mice. Psychopharmacology, 100, 27-30.

O'KeEFE, J., \& NADEL, L. (1978). The hippocampus as a cognitive map. Oxford: Oxford University Press, Clarendon Press.

OVERTON, D. A. (1974). Experimental methods for the study of statedependent learning. Federation Proceedings, 33, 1800-1813.

OVERTON, D. A. (1984). State dependent learning and drug discriminations. In L. L. Iverson, S. D. Iverson, \& S. H. Snyder (Eds.), Handbook of psychopharmacology (Vol. 18, pp. 59-127). New York: Plenum.

OVERTON, D. A. (1991). Historical context of state dependent learning and discriminative drug effects. Behavioural Pharmacology, 2, 253-264.

Petersen, R. C. (1979). Scopolamine state-dependent memory processes in man. Psychopharmacology, 64, 309-314.

Pusakulich, R. L., \& Nielson, H. C. (1976). Cue use in state-dependent learning. Physiological Psychology, 4, 421-428.

SMALL, W. S. (1901). Experimental study of the mental processes of the rat. American Journal of Psychology, 12, 206-239.

(Manuscript received July 3, 1998; revision accepted for publication June $15,1999$. 